\title{
Waterborne polyurethane and graphene/graphene oxide- based nanocomposites: Reinforcement and electrical conductivity
}

\author{
I. Larraza ${ }^{1}$, B. Alonso-Lerma ${ }^{2}$, K. Gonzalez ${ }^{1}$, N. Gabilondo ${ }^{1}$, R. Perez-Jimenez ${ }^{2,3}$, \\ M. A. Corcuera ${ }^{1}$, A. Arbelaiz ${ }^{1}$, A. Eceiza ${ }^{*}$ \\ ' 'Materials + Technologies’ Research Group (GMT), Department of Chemical and Environmental Engineering, Faculty of \\ Engineering of Gipuzkoa, University of the Basque Country, Pza Europa 1, 20018 Donostia-San Sebastian, Spain \\ ${ }^{2}$ CIC nanoGUNE BRTA, Tolosa Hiribidea 76, 20018 Donostia-San Sebastian 20018, Spain \\ ${ }^{3}$ Ikerbasque, Basque Foundation for Science, 48013 Bilbao, Spain
}

Received 5 February 2020 accepted in revised form 16 April 2020

\begin{abstract}
Polyurethane based materials show great potential for many applications, and their reinforcement with different kinds of nano-entities can improve their properties or supply them with new ones, widening their fields of applications to new opportunities. In this work, nanocomposites composed of a biobased waterborne polyurethane and carbonaceous reinforcements were prepared and characterized. Parting from graphite, graphene, and graphene oxide were obtained through a mechanical and a chemical route, respectively, and graphene oxide was reduced into graphene through a thermal process. Successful exfoliation, oxidation, and reduction processes were proven when characterizing graphene, graphene oxide, and reduced graphene oxide. Nancomposites reinforced with graphene and graphene oxide showed improved mechanical and thermomechanical properties, whereas they did not show electrical conductivity. Coatings of the systems with graphene and reduced graphene oxide were studied, to grant electrical properties to the composites. Electrical conductor materials were obtained after coating the systems, as shown by Electrostatic Force Microscopy and electrical conductivity measurements.
\end{abstract}

Keywords: polymer synthesis, nanocomposites, mechanical properties, coatings

\section{Introduction}

The increasing environmental awareness has pushed a significant growth in the development of greener materials than conventional ones, being the plastic industry, one of the main focuses of interest. Waterborne polyurethanes (WBPU) have come up as a promising alternative for their solvent-borne counterpart. Their lack of volatile organic compounds (VOC), as well as the possibility to use precursors from renewable sources, has turned them into a very attractive option [1-4]. Polyurethanes are segmented polymers composed of a hard segment (HS) and a soft segment (SS). The HS, formed by an isocyanate and a chain extender, provides the material with rigidity and strength, whereas the SS, formed by a polyol, grants flexibility to the polymer. Varying the chemical structure of constituents and the ratios of these segments, materials with tailor-made properties can be achieved [2, 5-7]. WBPUs have properties similar to those of conventional polyurethanes, thus also having a very wide field of applications, as can be textiles, coatings, adhesives, biomedical applications, and many more $[2,8-11]$.

By adding nano-reinforcement in small contents to polymeric matrices, the properties of a polymer can be significantly altered, granting them improved

${ }^{*}$ Corresponding author, e-mail: arantxa.eceiza@ehu.eus

(C) BME-PT 
mechanical and thermal stability or conferring them new functionalities, such as electrical conductivity. In this field, the use of carbonaceous materials has gained great popularity, thanks to the large natural availability of carbon and the great specific properties of carbon composed materials, as is the case of carbon nanotubes, fullerenes and graphite derived nanostructures, such as graphene $(\mathrm{G})$ [12].

Graphene is a two-dimensional hexagonal network of $\mathrm{sp}^{2}$ carbons, and it presents extraordinary properties, such as its high thermal and electrical conductivity. Graphene shows an extremely high aspect ratio, stiffness, and barrier properties, making it an excellent reinforcement for polymeric composites [13, 14]. Many different methods can be used in order to exfoliate graphene from graphite, the most common one being liquid phase exfoliation through sonication [15]. However, these methods can be time consuming and expensive. To overcome these drawbacks, an interesting alternative is the obtention of graphene oxide structures (GO) through chemical methods [16]. Graphene oxide also presents great specific properties, as well as interesting chemical and optical properties [17]. Its oxygenated groups also grant it strong hydrophilicity. By simply removing oxygencontaining groups from the surface, graphene can be obtained; this can be done through different methods, such as through thermal reduction, plasma or light exposure, or chemical reduction $[18,19]$.

WBPU/G composites can present new functionalities, opening the field to new applications. Polyurethane and graphene-based composites have shown great benefits for many applications, such as shape memory properties, oil adsorbent, gas barrier, and electromagnetic interference (EMI) shielding capacity [14, 20, 21]. In EMI applications, typically, metals are used; however, polymers with acquired electrical properties are a great replacement option for conventionally used materials. The low density, antiUV characteristic, mechanical properties, and electrical conductivity often showed by WBPU/G composites make them an interesting candidate for this application [22-26].

In this work, nanocomposites were prepared using a waterborne polyurethane as a matrix and either graphene or graphene oxide as reinforcements. Varying reinforcement type and content, different nanocomposites were prepared. To analyze possible improvements in matrix properties and, thus, new application opportunities, reinforcements, and composites were characterized. The successful process for obtaining $\mathrm{GO}$ and $\mathrm{G}$ was assessed by the characterization of the nano-entities, as well as the effect of their use on composites preparation, and the effect of the content of reinforcement used. Finally, in order to supply new functionalities, as electrical conductivity, the possibility of doing a graphene or reduced graphene oxide (rGO) coating was studied.

\section{Materials}

Graphene and graphene oxide were obtained from graphite flakes (Gr, Aldrich, St. Louis, USA). $\mathrm{N}$-methyl pyrrolidone (NMP, 97\%) used when exfoliating graphene was purchased from Sigma-Aldrich (St. Louis, USA). Sulfuric acid $\left(\mathrm{H}_{2} \mathrm{SO}_{4}, 96 \%\right)$, sodium nitrate $\left(\mathrm{NaNO}_{3}, 99 \%\right)$, potassium permanganate $\left(\mathrm{KMnO}_{4}, 99 \%\right)$, hydrogen peroxide $\left(\mathrm{H}_{2} \mathrm{O}_{2}, 30 \% \mathrm{w} / \mathrm{v}\right)$ and hydrochloric acid ( $\mathrm{HCl}, 37 \%)$ used to obtain GO were supplied by Panreac (Barcelona, Spain). Cyclohexane $(99.7 \%$ reagent grade) was purchased from Scharlab (Barcelona, Spain).

A difunctional polyol from a renewable source, Priplast $3192^{\circledR}\left(M_{\mathrm{w}}=2000 \mathrm{~g} \cdot \mathrm{mol}^{-1}\right)$, kindly supplied by Croda (Snaith, UK) was used in the synthesis of the polyurethane. Isophorone diisocyanate (IPDI, DESMODOUR I) was kindly supplied from Covestro (Leverkusen, Germany). 2,2-Bis(hydroxymethyl) propionic acid (DMPA, Aldrich) and ethylenediamine (EDA, Fluka, Buchs, Switzerland) were used as an internal emulsifier and as chain extender, respectively. To neutralize DMPA carboxylic groups, triethylamine (TEA), provided by Fluka, was employed, and dibutyltin dilaurate (DBTDL), provided from Aldrich, was used as a catalyst. Salvia officinalis $L$. dry material was purchased at a local herbalist.

\subsection{Preparation of waterborne polyurethanes (WBPU)}

A WBPU was synthesized using a two-step polymerization process, with a molar ratio of polyol/DMPA/ IPDI/EDA of 1/1.1/3.5/0.6, following a previously optimized protocol [27]. The reaction was carried out in a $250 \mathrm{ml}$ four-necked flask equipped with a mechanical stirrer, thermometer, and nitrogen inlet within a thermostatic bath. The reaction progress was monitored using the dibutylamine back titration method, according to ASTM D 2572-97. In the first step, the Priplast polyol, IPDI, and $0.037 \mathrm{wt} \%$ of DBTL respect to the prepolymer content were reacted at $100^{\circ} \mathrm{C}$ for $5 \mathrm{~h}$ under mechanical stirring, then 
the DMPA neutralized with TEA was added at $50{ }^{\circ} \mathrm{C}$ dissolved in acetone. The system was then cooled down to room temperature, where the phase inversion step was carried out by the dropwise addition of deionized water under vigorous stirring. Finally, the EDA chain extender was added, and the mixture was allowed to react for $2 \mathrm{~h}$ at $35^{\circ} \mathrm{C}$ under stirring, forming an aqueous dispersion with a solids content of $33 \mathrm{wt} \%$.

\subsection{Preparation of graphene, graphene oxide and reduced graphene oxide}

Graphene was obtained by a mechanical method through exfoliation of graphite, following the process described by Ugarte et al. [28]. Briefly, $20 \mathrm{~g}$ of graphite flakes were sonicated in $1500 \mathrm{ml} \mathrm{NMP}$ for 100 hours in an ultrasonic bath. After that, the dispersion was centrifuged in order to separate and keep the smaller fractions at $4000 \mathrm{rpm}$, filtered and left to dry, and graphene was obtained.

Graphene oxide was obtained through a modified Hummers' method [16]. Graphite flakes ( $1 \mathrm{~g})$ were mixed with $0.5 \mathrm{~g}$ of $\mathrm{NaNO}_{3}$ and $23 \mathrm{ml} \mathrm{H}_{2} \mathrm{SO}_{4}$ and left to react for half an hour, after that $3 \mathrm{~g}$ of $\mathrm{KMnO}_{4}$ was added, and the mixture was maintained under magnetic agitation in an ice water bath for $2 \mathrm{~h}$. Thereafter, it was heated to $35^{\circ} \mathrm{C}$ for $30 \mathrm{~min}$, and $46 \mathrm{ml}$ of water was added drop by drop. The mixture was heated to $98^{\circ} \mathrm{C}$ for $30 \mathrm{~min}$, and then $10 \mathrm{ml}$ of $\mathrm{H}_{2} \mathrm{O}_{2}$ was added slowly. Finally, the mixture was left to cool, and $150 \mathrm{ml}$ water was added. The mixture was washed through centrifugation, 5 times with $5 \% \mathrm{HCl}$ to get rid of $\mathrm{Mn}$ ions, and afterward with deionized water until a neutral $\mathrm{pH}$ was measured and, after that, it was filtered. The obtained graphene oxide was later sonicated with a probe sonicator for 3 hours and centrifuged at $4000 \mathrm{rpm}$ to obtain the smaller fractions; it was once again filtered and left to dry.

In order to reduce GO and achieve a graphene-like structure, a thermal treatment was done to the graphene oxide. $\mathrm{GO}$ was kept at $500{ }^{\circ} \mathrm{C}$ for $30 \mathrm{~min}$, during which time the oxygen-containing groups were reduced, and thus rGO was obtained.

The scheme of the obtention process of graphene, graphene oxide, and reduced graphene oxide through different methods is shown in Figure 1.

\subsection{Preparation of composites}

WBPU/graphene and WBPU/graphene oxide nanocomposite films were prepared by solvent casting. Different contents of GO were sonicated in water $\left(5 \mathrm{mg} \cdot \mathrm{ml}^{-1}\right)$ using a probe sonicator for 1 hour and were later added to $2.8 \mathrm{ml}$ of WBPU, thus varying the GO content in the composite. Deionized water was added to the mixtures until the final total volume $(12.9 \mathrm{ml})$ was the same for all systems. The mixtures were further sonicated for 1 hour in an ultrasonic bath and were later poured on Teflon molds and left to dry at room temperature for seven days, followed by three days under vacuum to ensure complete water removal. In the case of G, the use of surfactant was necessary for its dispersion in water, in this case, a plant extract, Salvia officinalis (E), was used as proposed by González et al. [29], with a weight ratio of G/E: $2 / 1$. For nanocomposite preparation, carbonaceous samples must be dispersed in water. Graphene shows poor dispersibility in water; however, after the incorporation of plant extracts, the graphene dispersion in
Graphite

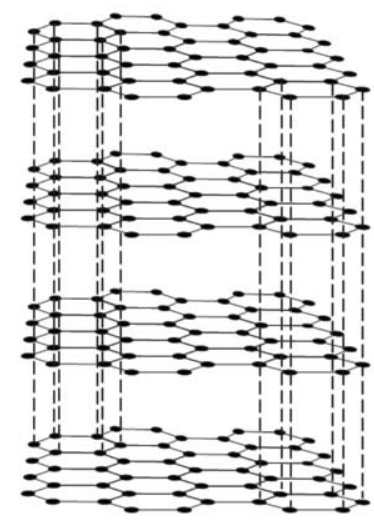

Graphene oxide

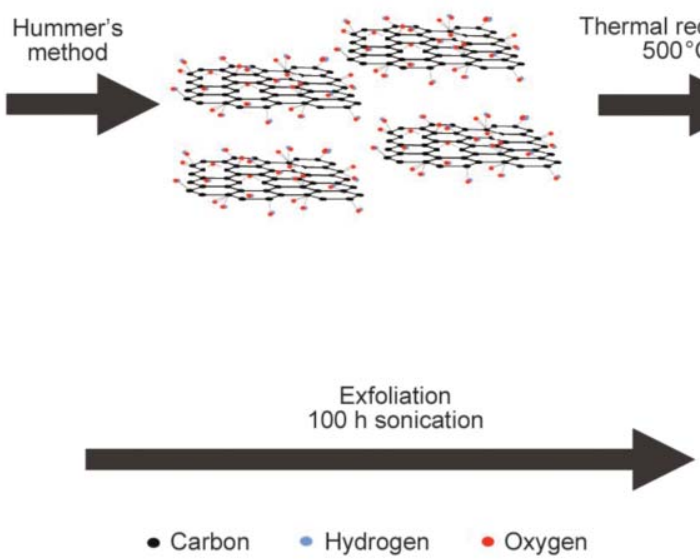

Reduced graphene oxide

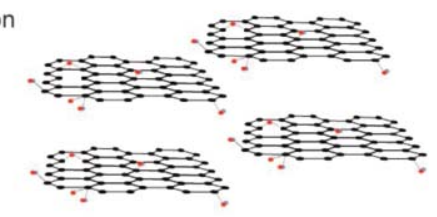

Graphene

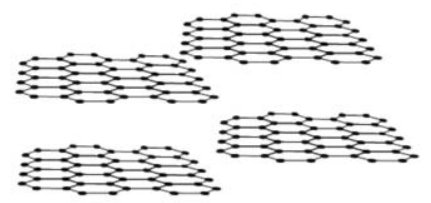

Figure 1. Scheme of the obtention process of graphene, graphene oxide and reduced graphene oxide. 
water improved. Plant extracts have shown the ability to act as natural surfactants [27] and have a great affinity with graphene due to the $\pi-\pi$ interactions [29]. On the other hand, thanks to the many functional groups on its surface, GO shows great water dispersibility. For composites films containing graphene, first, the Salvia extract was dissolved in water $\left(2.5 \mathrm{mg} \cdot \mathrm{ml}^{-1}\right)$ and then graphene was added $\left(5 \mathrm{mg} \cdot \mathrm{ml}^{-1}\right)$ and dispersed on it using a probe sonicator for 6 hours. Once dispersed, the same process was followed to form composites than with GO.

Films with 1, 3, and $5 \mathrm{wt} \%$ content of reinforcement were prepared in both cases; nanocomposites with different compositions were named $\mathrm{xGO}$ or $\mathrm{xGE}$, being $\mathrm{x}$ the content of reinforcement, GO referring to graphene oxide and GE to graphene with plant extracts in the aforementioned ratio. A WBPU film containing only Salvia extract was also prepared, in order to consider the effect of the addition of Salvia; for this, the highest content used for the $\mathrm{G}$ containing films were used. This film containing $2.5 \mathrm{wt} \%$ Salvia was named WBPU+E.

\subsection{Coating of WBPU and its composites}

To supply electrical conductivity to the systems, matrix, and composites films were coated using graphene and reduced graphene oxide. $\mathrm{G}$ and $\mathrm{rGO}$ were dispersed in cyclohexane $\left(10 \mathrm{mg} \cdot \mathrm{ml}^{-1}\right)$ in a sonication bath for 45 minutes. The matrix and nanocomposites were dipped in NMP in order to swell them and were afterward sonicated in the $\mathrm{G} /$ cyclohexane or $\mathrm{rGO} / \mathrm{cy}$ clohexane dispersion. The coated systems were cleaned with water to remove excess $\mathrm{G}$ and rGO that was not attached, and they were left to dry. Only two systems were prepared in each case, being them the matrix in both cases and the corresponding composite with the higher reinforcement content. Graphene coated systems were named WBPU/G, and $5 \mathrm{GE} / \mathrm{G}$ and reduced graphene oxide coated systems were named $\mathrm{WBPU} / \mathrm{rGO}$ and $5 \mathrm{GO} / \mathrm{rGO}$.

\section{Characterization}

\subsection{Transmission electron microscopy (TEM)}

The morphologies of the carbonaceous reinforcements were analyzed by TEM. Measurements were carried out on an FEI Titan Cubed G2 60-300 microscope (Thermofisher Scientific, Waltham, USA), equipped with a Schottky X-FEG field emission electron gun, monochromator and $\mathrm{CEOS} \mathrm{GmbH}$ spherical aberration (Cs) corrector on the image side. The microscope was operated at $80 \mathrm{kV}$. The third-order spherical aberration (Cs) was tuned to $-10 \mu \mathrm{m}$. Images were obtained for an underfocus of $-8 \mathrm{~nm}$ and were recorded on a CCD camera $(2 \mathrm{k} \times 2 \mathrm{k}$, Gatan UltraScan 1000, Gatan, California, USA), using exposition times of $1 \mathrm{~s}$ per image. TEM samples were prepared by dispersing $0.1 \mathrm{mg}$ of the carbonaceous sample in $20 \mathrm{~mL}$ of distilled water. In the case of graphene, Salvia extract was employed in order to disperse it.

\subsection{Elemental analysis (EA)}

EA was performed in order to determine the changes in the composition of the samples using a Euro EA3000 Elemental Analyzer of Eurovector (Pavia, Italy). In this way, the sample is combusted, and the resultant products are analyzed in a chromatographic column, where a thermal conductivity detector provides a signal of each element and then determines its percentage.

\subsection{X-ray diffraction (XRD)}

X-ray powder diffraction patterns were collected by using a Philips X'pert PRO automatic diffractometer (Malvern Panalytical, Malvern, UK) operating at $40 \mathrm{kV}$ and $40 \mathrm{~mA}$, in theta-theta configuration, a secondary monochromator with $\mathrm{Cu}-\mathrm{K} \alpha$ radiation $(\lambda=1.5418 \AA)$ and a PIXcel solid-state detector (active length in $2 \theta 3.347^{\circ}$ ). Data were collected from 2 to $40^{\circ} 2 \theta$ (step size 0.026 and time per step $80 \mathrm{~s}$ ) at room temperature. A fixed divergence and antiscattering slit giving a constant volume of sample illumination were used.

In order to determine the distance between planes, Bragg's law was used [30] (Equation (1)):

$n \lambda=2 d \sin \theta$

In which $n$ is a whole number, $\lambda$ is the wavelength of the incident radiation, $d$ is the shortest distance between two successive identical planes in the crystal, and $\theta$ is the angle of incidence of the primary rays.

\subsection{Raman spectroscopy}

Raman spectra were obtained with a Renishaw InVia spectrometer (Renishaw, Wotton-under-Edge, UK), coupled to a Leica microscope $(50 \times)$ with a laser of $514 \mathrm{~nm}$ wavelength (Modu Laser) at 5\% potency. Data were collected in the range of $150-3500 \mathrm{~cm}^{-1}$. 
Exposure time and accumulations were set at $20 \mathrm{sec}-$ onds and 5, respectively.

\subsection{Fourier transform infrared spectroscopy (FTIR)}

The characteristic functional groups of the used carbonaceous materials, WBPU and the composites were analyzed by Fourier transform infrared spectroscopy using a Nicolet Nexus spectrometer (Thermofisher Scientific, Waltham, USA) provided with an MKII Golden Gate accessory (Specac) with a diamond crystal at a nominal incidence angle of $45^{\circ}$ and $\mathrm{ZnSe}$ lens. Spectra were recorded in attenuated total reflection (ATR) mode between 4000 and $650 \mathrm{~cm}^{-1}$ averaging 32 scans with a resolution of $4 \mathrm{~cm}^{-1}$.

\subsection{Thermogravimetric analysis (TGA)}

The thermal stability of WBPU, the different nanoentities, and the composites was determined by thermogravimetric analysis. (TGA) performed in a TGA/ STDA 851 (Mettler Toledo, Columbus, USA) equipment. The samples, between 5-10 mg, were heated from 30 to $700^{\circ} \mathrm{C}$ in a nitrogen atmosphere at a scanning rate of $10^{\circ} \mathrm{C} \cdot \mathrm{min}^{-1}$.

\subsection{Electrical properties}

The electrical properties of polyurethane/graphene nanocomposites were analyzed by a Keithley 4200SCS (Keithley Instruments, Cleveland, USA) equipment for semiconductor analysis. Two-point measurements were carried out, performing 0-5 V linear scans, with $0.01 \mathrm{~V}$ step and compliance of $0.1 \mathrm{~A}$. Electrical resistance $(R)$ values were calculated from intensity vs. voltage curves. Resistivity $(\rho)$ and conductivity $(\sigma)$ values were calculated using Equations (2) and (3):

$$
\begin{aligned}
& \rho=R \frac{A}{L} \\
& \sigma=\frac{1}{\rho}
\end{aligned}
$$

where $R$ is the resistance, and $A$ and $L$ are the area and the length of the analyzed sample, respectively.

\subsection{Dynamic mechanical analysis (DMA)}

The viscoelastic behavior of the films was determined by dynamic mechanical analysis using an Eplexor $100 \mathrm{~N}$ analyzer Gabo (Selb, Germany) equipment. The measurements were carried out in tensile mode from -100 to $180^{\circ} \mathrm{C}$ at a scanning rate of
$2{ }^{\circ} \mathrm{C} \cdot \mathrm{min}^{-1}$. The initial strain was established as $0.05 \%$, and the operating frequency was fixed at $1 \mathrm{~Hz}$.

\subsection{Mechanical testing}

Mechanical tests were performed in an Instron 5967 testing machine (Instron, Norwood, USA) provided with a $500 \mathrm{~N}$ load cell and pneumatic grips to hold the samples. Samples were cut $(2.8 \mathrm{~mm}$ in width and $0.4 \mathrm{~mm}$ in thickness) and tested at a crosshead speed of $20 \mathrm{~mm} \cdot \mathrm{min}^{-1}$ at room temperature with a distance between clamps of $10 \mathrm{~mm}$. Tensile modulus $(E)$, stress at yield $\left(\sigma_{\mathrm{y}}\right)$, stress at break $\left(\sigma_{\mathrm{b}}\right)$, and elongation at break $\left(\varepsilon_{\mathrm{b}}\right)$ were determined from stress-strain curves of five specimens of each system.

\subsection{Electrostatic force microscopy (EFM)}

The electrical conductivity properties of systems were observed by electrostatic force microscopy. In EFM analysis, an electrostatic field is created between the tip and the substrate. Analyzing the phase shifts occurring due to electrostatic interactions conductive and insulating parts of the sample can be distinguished. Measurements were performed with Pt/Ir coated tips ( $75 \mathrm{kHz}$ resonant frequency) in a Dimension ICON (Bruker, Billerica, USA) equipment, working at lift mode $(100 \mathrm{~nm})$ and at room temperature. To analyze the distribution of the electrostatic field on the sample surface, bias voltages from 0 to $12 \mathrm{~V}$ were applied to the cantilever/tip system. For each system, a sample size of $2 \times 2 \mathrm{~mm}$ was cut and stuck to an AFM stainless steel specimen disk.

\subsection{Scanning electron microscopy (SEM)}

The morphology of the coated systems was studied through scanning electron microscopy. Images were obtained with an FEI ESEM Quanta 200 (Thermofisher Scientific, Waltham, USA), operating at 5$20 \mathrm{kV}$. Samples were held with a clamp, and the analyses took place under vacuum.

\section{Results and discussion}

\subsection{Characterization of carbonaceous samples}

Graphene, graphene oxide, and reduced graphene oxide were characterized by several techniques. In order to study sample compositions and observe the changes that have taken place during the production of each carbonaceous material, an elemental analysis test has been carried out, where contents of $\mathrm{C}, \mathrm{H}$, and 
Table 1. Elemental analyses for the content of $\mathrm{C}, \mathrm{H}$, and $\mathrm{O}$ in graphite, graphene, graphene oxide and reduced graphene oxide.

\begin{tabular}{|l|c|c|c|}
\hline & $\begin{array}{c}\mathbf{C} \\
{[\mathbf{\%}]}\end{array}$ & $\begin{array}{c}\text { H } \\
{[\mathbf{\%}]}\end{array}$ & $\begin{array}{c}\text { O } \\
{[\mathbf{\%}]}\end{array}$ \\
\hline $\mathrm{Gr}$ & 95.85 & 1.55 & - \\
\hline $\mathrm{G}$ & 94,99 & 1.91 & 2.23 \\
\hline $\mathrm{GO}$ & 55.55 & 2.86 & 38.28 \\
\hline $\mathrm{rGO}$ & 90.74 & 2.31 & 6.20 \\
\hline
\end{tabular}

O have been measured. The results can be seen in Table 1.

Graphite and graphene are mainly composed of carbon, as shown in the literature [31, 32]; however, they show some traces of $\mathrm{H}$ and $\mathrm{O}$. For GO, a very significant part of its composition is formed by $\mathrm{O}$, proving the effective oxidation process that has taken place during its preparation. For rGO, the oxygen value significantly decreases to lower percentage values, whereas the composition of carbon increases greatly, part of the oxygen-containing functional groups of graphene oxide are reduced, and this is reflected in the obtained results. However, the values of oxygen and hydrogen content prove just a partial reduction, meaning that some oxidized groups remain on the rGO structure, which is in agreement with literature results [33].

FTIR spectra of all carbonaceous structure reinforcements show changes taken place during the processes of obtaining $\mathrm{G}, \mathrm{GO}$, and $\mathrm{rGO}$, if compared with graphite (Figure 2). Graphene spectrum shows bands around 3435 and $1655 \mathrm{~cm}^{-1}$, attributed to $\mathrm{OH}$ stretching and bending vibrations, respectively, suggesting the presence of water or some hydroxyl-containing groups in the structure [15]. Moreover, low-intensity bands can be observed at 2929 and $2854 \mathrm{~cm}^{-1}$ related to $\mathrm{C}-\mathrm{H}$ stretching vibration, in agreement with

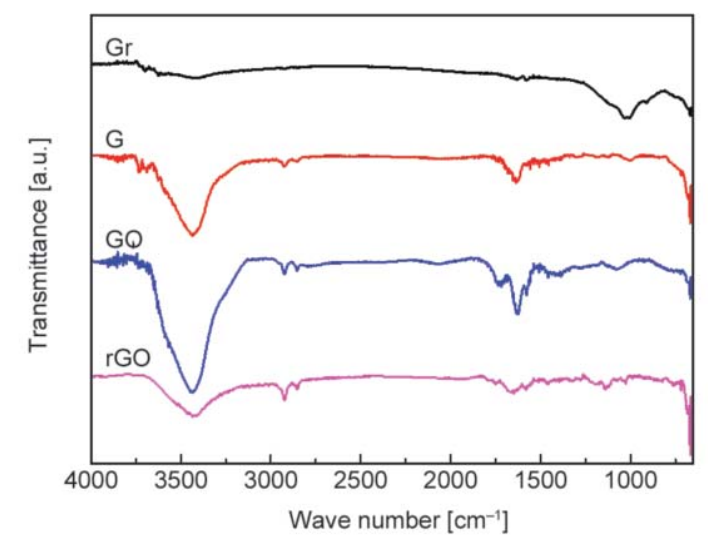

Figure 2. FTIR spectra of graphite, graphene, graphene oxide and reduced graphene oxide. elemental analysis. GO shows a very intense $\mathrm{OH}$ band at $3404 \mathrm{~cm}^{-1}$, as well as a carbonyl band at $1735 \mathrm{~cm}^{-1}$, and bands at 1400 and $1050 \mathrm{~cm}^{-1}$, attributed to tertiary $\mathrm{C}-\mathrm{OH}$ groups and $\mathrm{C}-\mathrm{O}$ stretching, respectively [34-36]. Moreover, bands related to $\mathrm{C}-\mathrm{H}$ stretching vibration can be seen. $\mathrm{GO}$ also shows the band related to $\mathrm{O}-\mathrm{H}$ bending at $1630 \mathrm{~cm}^{-1}$. For rGO these bands still remain in the spectrum, since a complete reduction was not achieved. However, a decrease in intensity and wavenumber shifts prove changes in the system.

TGA analyses were performed for all four systems (Figure 3). Graphite thermogram shows almost no weight loss throughout the temperature thermal scan, proving a really high thermal stability, characteristic of well-ordered fully carbonaceous structures. For graphene, a small weight loss was observed starting above $100^{\circ} \mathrm{C}$, taking place gradually in a wide temperature interval and probably due to the presence of defects [37].

In the case of GO, two major weight drops are observed in the weight evolution with temperature curve and two peaks in the derivative curve (DTG), one at a low temperature, attributed to absorbed water and the second and most significant one, around $250^{\circ} \mathrm{C}$, was attributed to the decomposition of oxygen-containing functional groups (i.e., $\mathrm{C}=\mathrm{O}, \mathrm{C}-\mathrm{O}-\mathrm{C}$ and $-\mathrm{OH}$ ) [38]. In the case of $\mathrm{rGO}$, a small weight loss and a peak in the DTG curve related to water were observed at low temperatures. During the degradation process, however, the sample remained quite stable for the exception of a slight weight loss around $660^{\circ} \mathrm{C}$, attributed to the remaining oxygen-containing groups [38], which is in agreement with elemental analysis values. For comparative purposes, the weight loss and DTG curves of Salvia were included

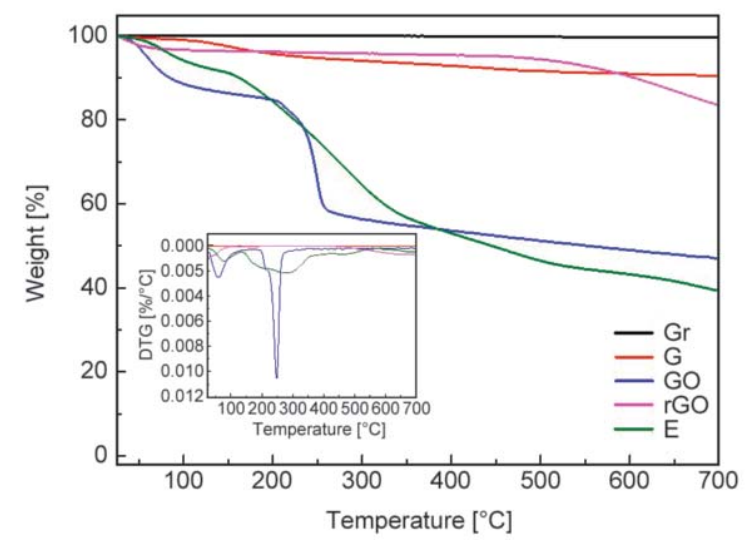

Figure 3. TGA and DTG of graphite, graphene, graphene oxide, reduced graphene oxide, and Salvia extract. 
in Figure 3. After the initial humidity loss, most of the weight loss occurred between 150 and $400^{\circ} \mathrm{C}$, attributed to the decomposition of polysaccharides, and a $40 \%$ of residue remained after the degradation process, as also seen with other plant extracts $[39,40]$.

For $\mathrm{G}$ and GO, TEM images were obtained in order to observe their morphology (Figure 4). Figures 4a and $4 \mathrm{~b}$ on the left show well-defined flakes with lengths of $650 \pm 170$ and $875 \pm 260 \mathrm{~nm}$ for $\mathrm{G}$ and GO, respectively. High-resolution TEM (HRTEM) images (image in the middle) showed highly ordered zones, from which atomic distribution was seen, and the distance between atoms was measured. Zoomed images showed a hexagonal-shaped atomic distribution with an atom sitting on the center of the hexagon (image on the right). Measured distances between atoms were of 0.26 , and $0.25 \mathrm{~nm}$ for GO and G. This distribution and distance are attributed to the presence of at least a bi-layer structure, as seen in literature [41], where the second layer does not lie directly under the layer above but is slightly displaced from it and thus these data are obtained.

For graphene, the flakes presented a more damaged structure than graphene oxide. Moreover, graphene flakes seemed to be attached to the extracts (see arrow) and some holes appear on its structure (circled in yellow in Figure 4a). HRTEM images were slightly more diffused, and the atomic distribution was harder to distinguished, probably due to the disturbances caused by the presence of the Salvia.

In order to study the crystalline structures of the prepared carbonaceous reinforcements, X-Ray analyses were performed, and the resulting diffractograms are shown in Figure 5. The diffractogram corresponding to graphite shows a very pronounced peak at $2 \theta=$ $26.63^{\circ}$ corresponding to $(002)$ plane $[17,42]$. This peak is also observed in the graphene diffractogram, though less sharp and with very reduced intensity. For GO diffractogram, a small peak at $26^{\circ}$ is still present, meaning that the system is not completely oxidized, maintaining still some original graphitic

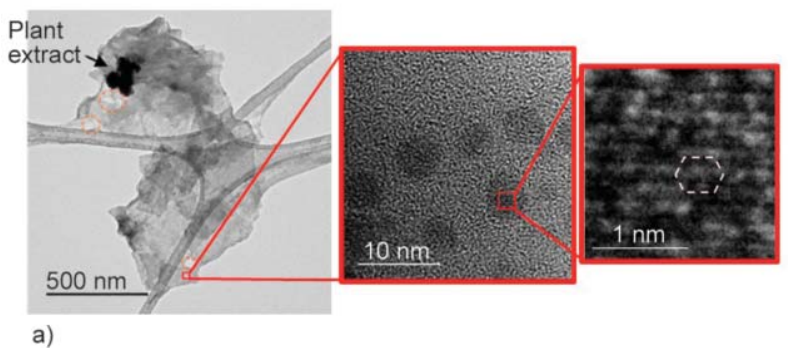

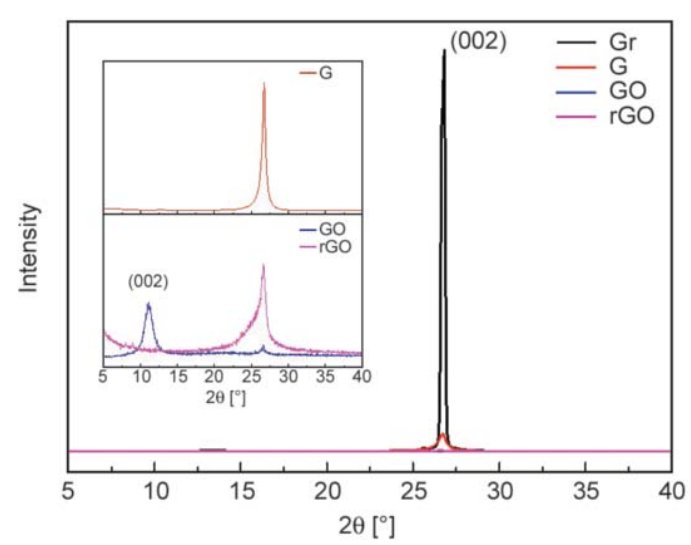

Figure 5. X-ray diffractograms for graphite, graphene, graphene oxide and reduced graphene oxide.

structures. However, the main peak for GO is located at $2 \theta=11.2^{\circ}$. This new peak is attributed to the intercalation of oxygen-containing groups between GO layers [17]. The $2 \theta$ value at which this peak appears depends on the degree of oxidation and the newly formed groups. In our case, this value is a little higher than those found in literature, proving incomplete oxidation $[42,43]$. In the case of rGO the peak shifted back to $2 \theta=26.63^{\circ}$, showing a similar curve to that of graphene; however, the peak was not as sharp. This wider peak was attributed to a not complete reduction of the GO, since partially reduced graphene oxide structures tend to present the peak at lower $2 \theta$ values than graphene [44]. This partial reduction is in agreement with EA and FTIR results. Significantly lower intensities shown by G, GO, and $\mathrm{rGO}$ proved good exfoliation from the parting graphite structure during the process of obtention of the nano-reinforcements [45].

The interplanar distances were calculated according to Equation (1). For Gr, G, GO, and rGO the interplanar distances for the (002) plane was calculated, being it $0.335 \mathrm{~nm}$ for $\mathrm{Gr}$ and $\mathrm{G}$, and $0.790 \mathrm{~nm}$ for GO. Distance between planes became larger for GO due to the presence of oxygen-containing groups, thus enlarging the distance between layers. For rGO the interplanar distance calculated according to the $2 \theta$

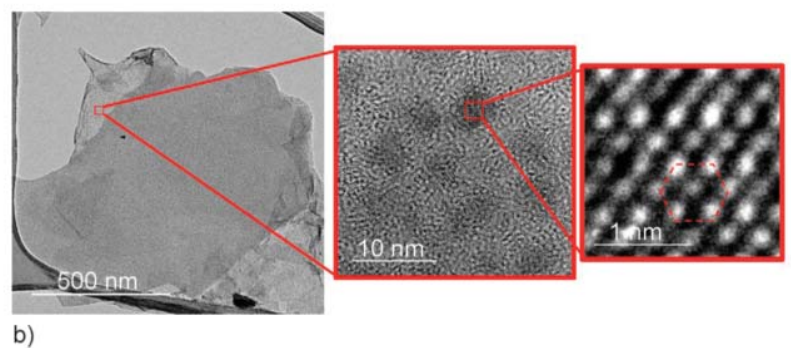

Figure 4. TEM images for a) graphene and b) graphene oxide. 
value of the peak maximum went back to $0.335 \mathrm{~nm}$; however, the broader peak reflects a not so constant distance, but a range due to the mixture of different degrees of oxidation of the system.

All four systems, Gr, G, GO and rGO were also analyzed by Raman spectroscopy, in order to obtain information on structural changes in the systems. Data obtained from Raman spectra, both the peaks' Raman shift $\left[\mathrm{cm}^{-1}\right]$ and intensity $(I)$, are shown in Table 2 . All spectra showed the typical bands of carbon-based materials: a $G$ peak around $1570 \mathrm{~cm}^{-1}$, attributed to $\mathrm{sp}^{2}$ atoms, a $D$ peak near $1354 \mathrm{~cm}^{-1}$, related to the presence of defects, and a $2 D$ band at $2700 \mathrm{~cm}^{-1}$ related to the second-order of zone boundary phonons [28]. The $D$ peak, related to the amount of defects in the structure, is usually used to measure the level of disorder.

The Raman values of graphite show a very intense $G$ peak and a relatively intense $2 D$ band, whereas a very low intense $D$ peak is obtained, indicating a low degree of disorder. For exfoliated graphene, $D$ peak significantly shits to lower wavenumber and increases in intensity, being this peak at $1350 \mathrm{~cm}^{-1}$ prominent. When defects are present, a band around $2950 \mathrm{~cm}^{-1}$ is also seen as a combination of the $D$ and $D^{\prime}$ phonons $[46,47]$, which could be seen in the graphene diffractogram. The spectrum for GO shows peaks with much higher intensity in both 1351 and $2930 \mathrm{~cm}^{-1}$, which could be attributed to the formation of the newly oxidized groups and, therefore, an increase in the disorder of the system. The $G$ peak also significantly shifted to higher wavenumbers, from $1570 \mathrm{~cm}^{-1}$ in $\mathrm{Gr}$ to $1599 \mathrm{~cm}^{-1}$ in GO, which is attributed to the formation of new sp $\mathrm{s}^{3}$ carbon atoms in the graphite lattice [48]. The $2 D$ band intensity decreases due to the breaking of the stacking order. For rGO, spectrum values show reduced defect peaks, signaling the effective reduction of the oxygen-containing groups and a quite good reorganization of the structure.

In order to analyze the degree of disorder, the intensity ratio of $D$ and $G$ bands $\left(I_{\mathrm{D}} / I_{\mathrm{G}}\right)$ is often used [28]. The $I_{\mathrm{D}} / I_{\mathrm{G}}$ ratio was calculated for graphite, graphene, $\mathrm{GO}$ and $\mathrm{rGO}$ and values of $0.06,0.56,0.86$, and 0.20 were obtained, respectively. These values showed the almost complete lack of defects in the graphite structure, as well as the formation of them during the obtaining of G and GO. During the reduction of GO, the elimination of the oxygen-containing groups resulted in a less defected structure for rGO. Moreover,
Table 2. Raman spectra values, Raman shift $\left[\mathrm{cm}^{-1}\right]$ and intensity, of graphite, graphene, graphene oxide and reduced graphene oxide.

\begin{tabular}{|l|c|c|c|c|c|c|c|c|}
\hline & $\begin{array}{c}\boldsymbol{D} \\
{\left[\mathbf{c m}^{-1}\right]}\end{array}$ & $\boldsymbol{I}_{\mathbf{D}}$ & $\begin{array}{c}\boldsymbol{G} \\
{\left[\mathbf{c m}^{-\mathbf{1}}\right]}\end{array}$ & $\boldsymbol{I}_{\mathbf{G}}$ & $\begin{array}{c}2 \boldsymbol{D} \\
{\left[\mathbf{c m}^{-\mathbf{1}}\right]}\end{array}$ & $\boldsymbol{I}_{\mathbf{2 D}}$ & $\begin{array}{c}\boldsymbol{D}+\boldsymbol{D}^{\prime} \\
{\left[\mathbf{c m}^{-\mathbf{1}}\right]}\end{array}$ & $\boldsymbol{I}_{\mathbf{D}+\mathbf{D}^{\prime}}$ \\
\hline $\mathrm{Gr}$ & 1354 & 622 & 1570 & 9794 & 2725 & 4551 & - & - \\
\hline $\mathrm{G}$ & 1350 & 5611 & 1578 & 9942 & 2704 & 5333 & 2942 & 1183 \\
\hline $\mathrm{GO}$ & 1351 & 8515 & 1599 & 9905 & 2742 & 3703 & 2930 & 5081 \\
\hline rGO & 1347 & 1981 & 1592 & 9972 & 2699 & 4689 & 2946 & 547 \\
\hline
\end{tabular}

the intensity ratio between $2 D$ and $G$ peaks $\left(I_{2 \mathrm{D}} / I_{\mathrm{G}}\right)$ is often used to determine the layering of the materials. Luo et al. [49] found that a ratio $>1.6$ belongs to monolayer structures, whereas a ratio around 0.8 to bilayer structure. Ratio values lower than this correspond to multilayer structures. This calculation was done for $\mathrm{G}, \mathrm{GO}$ and $\mathrm{rGO}$ and values of 0.54 , 0.37 and 0.47 were obtained, respectively, suggesting an intensely exfoliated structure for both graphene and reduced graphene oxide and slightly less so for graphene oxide.

The electrical conductivity of the systems was analyzed, measuring transmitted current when voltage ranging from 0 to $5 \mathrm{~V}$ was applied, and resistivity and conductivity values were calculated using Equations (2) and (3). Both G and rGO showed conductivity proper of semiconductors, being it higher for graphene than for reduced graphene oxide [50], $3.1 \pm 1.2$ and $(5.3 \pm 1.5) \cdot 10^{-3} \mathrm{~S} \cdot \mathrm{cm}^{-1}$, respectively. Graphene oxide, as expected, showed no electrical conductivity $(5.6 \pm 3.8) \cdot 10^{-7} \mathrm{~S} \cdot \mathrm{cm}^{-1}$. Graphene's measured conductivity was similar to values obtained in literature and lower than those found for graphite [50]. rGO showed lower conductivity than graphene due to a structure with some remaining oxidized groups impeding a better transfer of the electric charge. Graphite has anisotropic electrical properties that depend on the basal plane this property is being measured on. The conductivity values for graphite are around $10^{4} \mathrm{~S} \cdot \mathrm{cm}^{-1}$ in a $\|$ basal plane and around $10^{0} \mathrm{~S} \cdot \mathrm{cm}^{-1}$ in a $\perp$ basal plane [51].

\subsection{Characterization of composites}

Figure 6 shows WBPU and composite films with $5 \mathrm{wt} \%$ of graphene stabilized with plant extracts (5GE) and graphene oxide (5GO). For comparative purposes, the film formed by WBPU and plant extracts (WBPU+E) is shown. Differences in color and opacity can be seen with the addition of plant extracts, graphene, and graphene oxide. The addition of plant extract results in green-brown tonality films, 


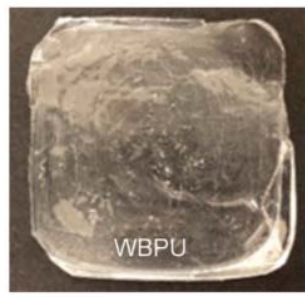

a)

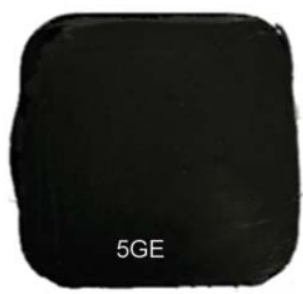

c)

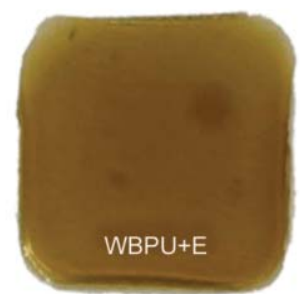

b)

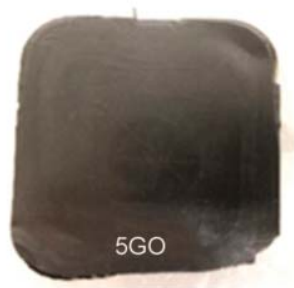

d)
Figure 6. Photographs of the prepared a) WBPU, b) WBPU+E, c) $5 \mathrm{GE}$ and d) $5 \mathrm{GO}$.

the addition of graphene results in a blacker color in the films, however, with graphene oxide, the color of the film has a browner tonality, in agreement with graphene and graphene oxide colors. The photographs indicated that the distribution of nano-reinforcements was homogeneous in the polymer matrix.

The FTIR spectrum of the WBPU matrix is shown in Figure 7. Characteristic absorption bands are observed at $3369 \mathrm{~cm}^{-1}$, attributed to hydrogen-bonded $\mathrm{N}-\mathrm{H}$ groups, at $1731 \mathrm{~cm}^{-1}$ assigned to the carbonyl vibration of the polyol and urethane groups, at $1645 \mathrm{~cm}^{-1}$ from the carbonyl group stretching vibration of urea group, at $1545 \mathrm{~cm}^{-1}$ assigned to the $\mathrm{C}-\mathrm{N}$ stretching vibration and $\mathrm{N}-\mathrm{H}$ bending of urethane and urea groups and between 1250 and $1000 \mathrm{~cm}^{-1}$ attributed to the $\mathrm{C}-\mathrm{O}$ stretching vibrations [52-54]. Figure 7 also shows FTIR spectra for WBPU+E, $5 \mathrm{GE}$, and $5 \mathrm{GO}$ composites, in which some slight differences between neat WBPU matrix and composites

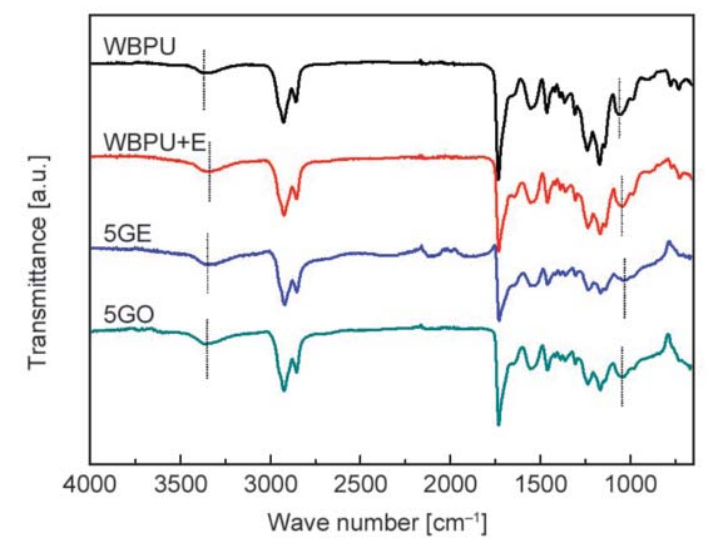

Figure 7. FTIR spectra of WBPU, WBPU+E, 5GE and 5GO. can be seen. In the case of composites containing $\mathrm{GO}$, it can be seen that the band centered around $3369 \mathrm{~cm}^{-1}$ shifts to lower wavenumbers compared to neat WBPU, suggesting hydrogen bonding interactions between the matrix and GO [55]. For composites reinforced with graphene, this band also shifts to lower wavenumber, indicating some interactions taken place. In this case, considering the lack of $\mathrm{OH}$ groups in graphene, this could be due to interactions between the WBPU and the added plant extracts, as can be seen in the spectrum of WBPU+E. The $\mathrm{C}-\mathrm{O}$ stretching peak at $1061 \mathrm{~cm}^{-1}$ is also affected and shifts to lower wavenumbers, in both GE and GO containing systems.

To better understand the interactions taken place in the prepared systems, a schematic representation of WBPU/GE and WBPU/GO systems can be seen in Figure 8. H-bonding observed in FTIR analyses can be seen in this representation. In the case of composites containing $\mathrm{GO}, \mathrm{H}$-bondings are formed with the functional groups in the structure of the nano-reinforcements. However, in the case of graphene, there are no such groups on its structure; therefore, H-bonding observed by FTIR are attributed to interactions between WBPU and Salvia extract, since extract is composed mainly by terpenoids, phenolic acids and diterpenes [27].

The reinforcement effect can be observed when studying their mechanical properties (Table 3).
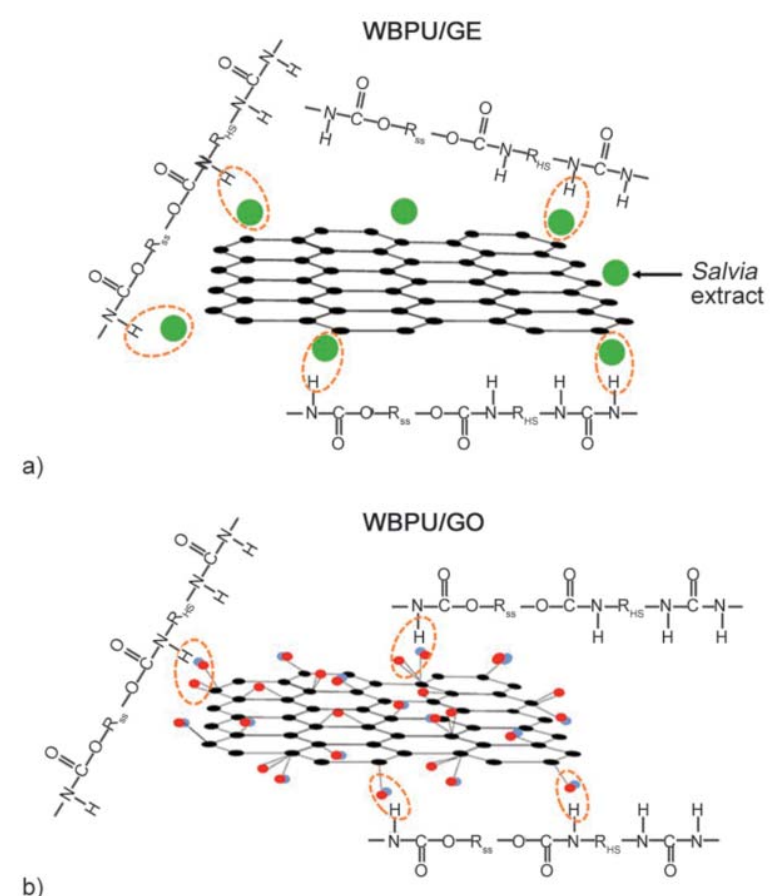

Figure 8. Schematic representation of interaction in a) WBPU/GE and b) WBPU/GO composites. 
Table 3. Young modulus, stress at yield, stress at break and strain at break values, for WBPU and reinforced composites.

\begin{tabular}{|l|c|c|c|c|}
\hline & $\begin{array}{c}\text { Modulo } \\
{[\mathbf{M P a}]}\end{array}$ & $\begin{array}{c}\text { Stress at } \\
\text { yield } \\
{[\mathrm{MPa}]}\end{array}$ & $\begin{array}{c}\text { Stress at } \\
\text { break } \\
{[\mathbf{M P a}]}\end{array}$ & $\begin{array}{c}\text { Strain at } \\
\text { break } \\
{[\%]}\end{array}$ \\
\hline WBPU & $37.9 \pm 6.2$ & $2.7 \pm 0.1$ & $7.2 \pm 1.6$ & $739.6 \pm 170.2$ \\
\hline WBPU+E & $43.9 \pm 3.4$ & $2.6 \pm 0.2$ & $15.0 \pm 4.2$ & $854.0 \pm 135.1$ \\
\hline $1 \mathrm{GE}$ & $45.6 \pm 4.8$ & $2.6 \pm 0.2$ & $18.2 \pm 3.7$ & $881.2 \pm 185.6$ \\
\hline $3 \mathrm{GE}$ & $49.3 \pm 5.3$ & $2.9 \pm 0.1$ & $15.9 \pm 5.0$ & $733.5 \pm 77.9$ \\
\hline $5 \mathrm{GE}$ & $67.0 \pm 0.3$ & $3.1 \pm 0.2$ & $10.5 \pm 0.6$ & $611.8 \pm 122.6$ \\
\hline $1 \mathrm{GO}$ & $44.4 \pm 3.6$ & $2.6 \pm 0.1$ & $8.2 \pm 2.6$ & $599.1 \pm 58.8$ \\
\hline $3 \mathrm{GO}$ & $52.4 \pm 7.6$ & $4.0 \pm 0.3$ & $12.4 \pm 2.0$ & $699.8 \pm 108.1$ \\
\hline $5 \mathrm{GO}$ & $76.9 \pm 8.2$ & $5.5 \pm 0.3$ & $9.3 \pm 0.3$ & $453.4 \pm 23.7$ \\
\hline
\end{tabular}

Young modulus increased for all composites, and the increase was proportional to the reinforcement content. The effect was more significant in the case of GO containing composites, which was also seen for stress at yield values [56]. On the other hand, stress at break was also improved and the improvement was higher in composite reinforced with graphene. These higher stress at break values could also be due to a reinforcement effect supplied by the Salvia extract, since a very significant improvement in the properties is observed for WBPU+E system. However, in both composites reinforced with $\mathrm{G}$ and GO, it could be seen that for higher contents tensile strength values started to drop, probably attributed to the formation of agglomerations. Regarding the strain at break, a tendency to decrease with the addition of nano-reinforcements was seen, as was to be expected for GO composites [57]. In the case of WBPU/GE composites, the effect of the Salvia, as well as an excellent interfacial adhesion [58], provided higher stress at break values and impeded a sharp decrease in this property.

The reinforcement effect on the dynamic mechanical behavior of the nanocomposites can be seen in Figure 9. A higher storage modulus can be appreciated for composites throughout the whole range of temperature compared to the neat WBPU matrix. A significant increase in the stability of the systems is also observed $[20,58,59]$. This effect is more significant for composites reinforced with GO, probably due to more favored direct interaction between matrix and reinforcement. H-bondings between WBPU and GO, observed in FTIR studies, could reduce the mobility of the polyurethane chains and increase stiffness, resulting in materials with higher storage modulus [60, 61]. Furthermore, the high modulus and specific

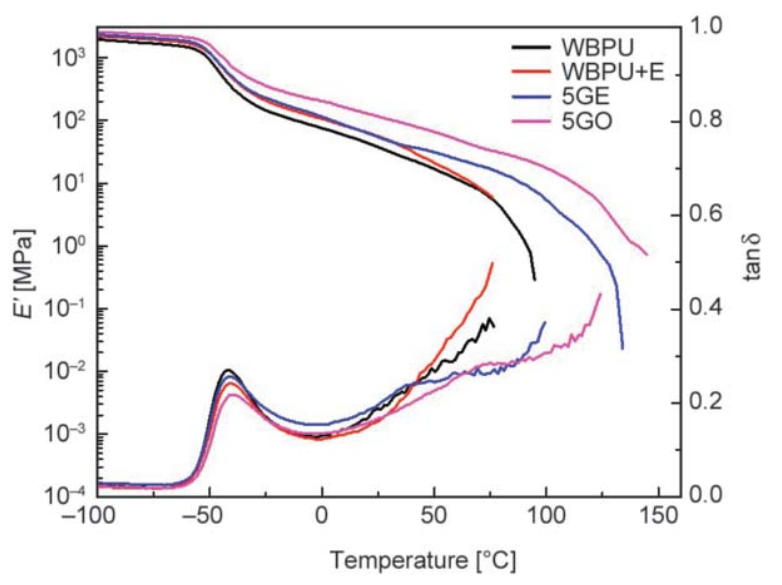

Figure 9. Dynamic-mechanical curves of neat WBPU matrix and composites reinforced with $5 \mathrm{wt} \%$ of $\mathrm{G}$ and GO.

surface area of the reinforcement could also enhance the stiffness of the WBPU [59]. This reinforcement effect and higher stiffness were observed in tensile properties, where both Young modulus and stress values increased with the addition of GO, whereas elongation at break values dropped.

The storage modulus and stability of 5GE composite also improved; however, this improvement is less significant than with GO, having WBPU/GE composites lower modulus and stability than WBPU/GO composites, probably due to the presence of Salvia interfering in the matrix/graphene interactions.

The thermal degradation of WBPU is shown in Figure 10. A two-step degradation process can be seen for WBPU, where the first one encompasses the degradation of the HS between 240 and $400^{\circ} \mathrm{C}$, and it is composed by two peaks attributed to the urea and the urethane groups, followed by the degradation of the SS around $450^{\circ} \mathrm{C}[62,63]$. When studying the thermal properties of composites, no significant

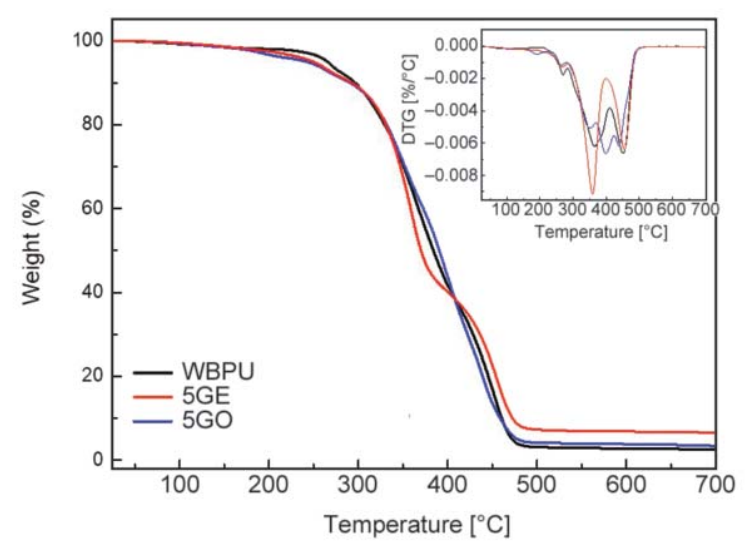

Figure 10. TGA and DTG of WBPU and $5 \mathrm{wt} \%$ reinforced composites. 
changes were observed, where the same trend is followed with no significant temperature changes. Similar thermal degradation behavior has been previously reported in the literature $[64,65]$. However, for GO composites with the higher reinforcement content, a new early degradation peak at $190^{\circ} \mathrm{C}$ is observed, probably related to the degradation of oxygen-containing groups. Composites thermal stability was not improved by the addition of either GO or G. Char residue increases as does reinforcement content, and it is more noticeable in the case of nanocomposites with graphene, due to both the presence of Salvia extract as previously observed and the higher thermal stability of graphene.

The electrical properties of GE containing composite films were studied, and neither of the films showed a conductive character. Graphene flakes seemed to have stayed embedded in the polyurethane matrix, or the $\mathrm{G}$ content is too low and thus were not able to form a conductive net.

\section{Characterization of coated systems}

WBPU and composites, both with a $5 \mathrm{wt} \%$ of GE and $\mathrm{GO}$, were coated with graphene and reduced graphene oxide (WBPU/G and 5GE/G, and WBPU/rGO and $5 \mathrm{GO} / \mathrm{rGO}$, respectively) in order to supply them conductivity. The electrical properties of the coated systems were analyzed in order to assess a successful conductivity. All systems showed electrical conductive capacity, however, coated WBPU showed higher electrical resistance, $(155.0 \pm 76.0) \cdot 10^{6} \Omega$ for WBPU/ $\mathrm{G}$ and $(142.1 \pm 20.5) \cdot 10^{6} \Omega$ for WBPU/rGO, whereas composites had significantly lower resistance values, $(6.6 \pm 1.7) \cdot 10^{6} \Omega$ for $5 \mathrm{GE} / \mathrm{G}$ and $(2.7 \pm 1.3) \cdot 10^{6} \Omega$ for $5 \mathrm{GO} / \mathrm{rGO}$. This higher conductivity was attributed to a better affinity with the reinforced composites during the coating process. rGO coated systems showed slightly higher conductivity that system coated with

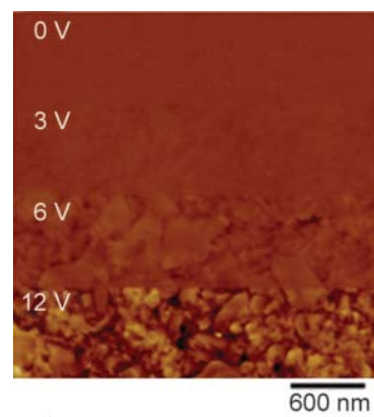

a)
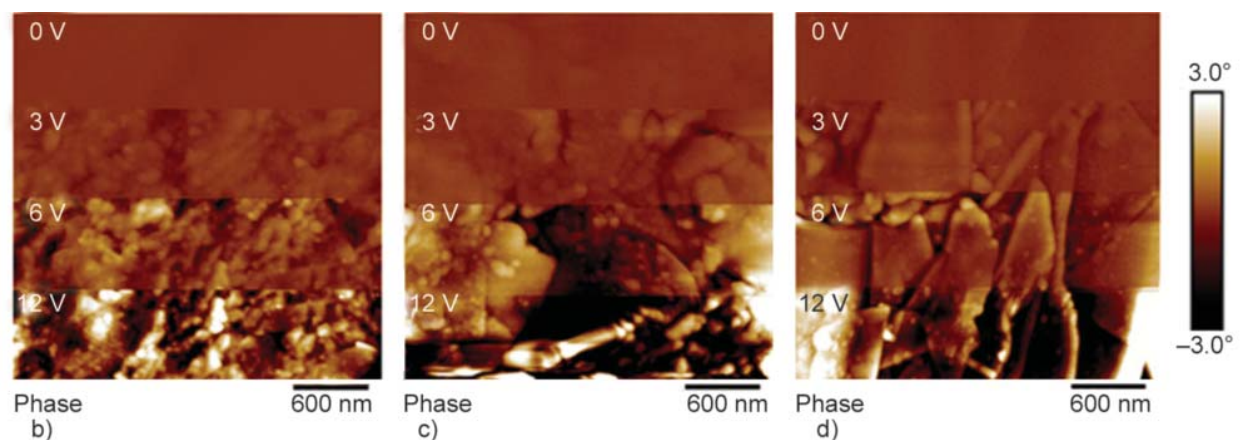

Figure 11. EFM phase images at $0,3,6$ and $12 \mathrm{~V}$ for a) $\mathrm{WBPU} / \mathrm{G}, \mathrm{b}) 5 \mathrm{GE} / \mathrm{G}, \mathrm{c}$ ) $\mathrm{WBPU} / \mathrm{rGO}$ and d) $5 \mathrm{GO} / \mathrm{rGO}$ (Image size:
$3 \times 3 \mu \mathrm{m})$.

Figure 11. EFM phase images at $0,3,6$ and $12 \mathrm{~V}$ for a) WBPU/G, b) $5 \mathrm{GE} / \mathrm{G}$, c) WBPU/rGO and d) $5 \mathrm{GO} / \mathrm{rGO}$ (Image size:
$3 \times 3 \mu \mathrm{m})$.
G. The remaining oxidized groups in the rGO structure help improve interaction, and a thicker coating was achieved in this case (see SEM images in Figure 13).

To better analyze the electrical properties of the systems, EFM analyses were also performed. Scans were done at $0,3,6$, and $12 \mathrm{~V}$. When voltage is applied, only conductor materials are capable of interacting with the cantilever and phase images are obtained, all systems showed to have an electrically conductive surface. As in the previous electrical resistance results, EFM analysis shows better conductivity for composites, producing brighter images (Figure 11).

To evaluate possible damage of the coated composites during the coating process, DMA of the coated systems were also performed. Sample curves before coating procedure (WBPU, 5GE, and 5GO) and after (WBPU/G, 5GE/G, WBPU/rGO, and 5GO/rGO) are compared in Figure 12. Results show, in general, similar values for coated and not coated systems. A small decrease in the storage modulus throughout the temperature scan can be observed for coated systems,

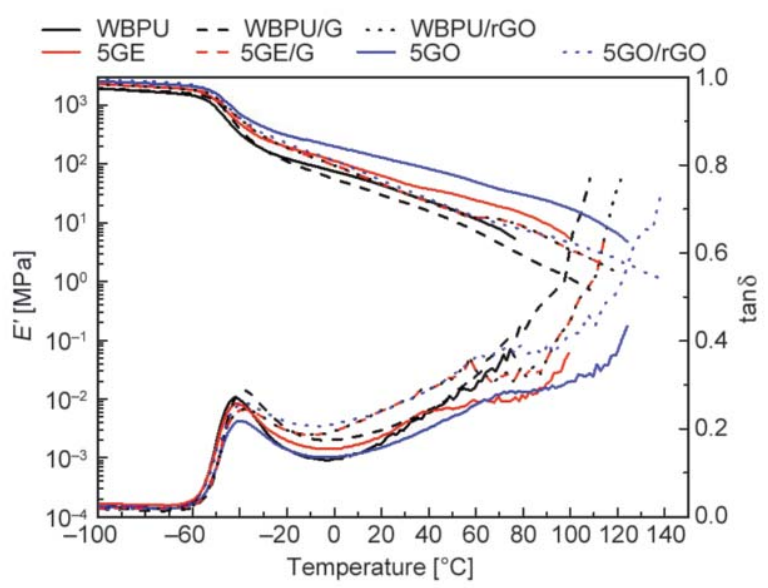

Figure 12. Dynamic-mechanical curves of coated and uncoated systems. 

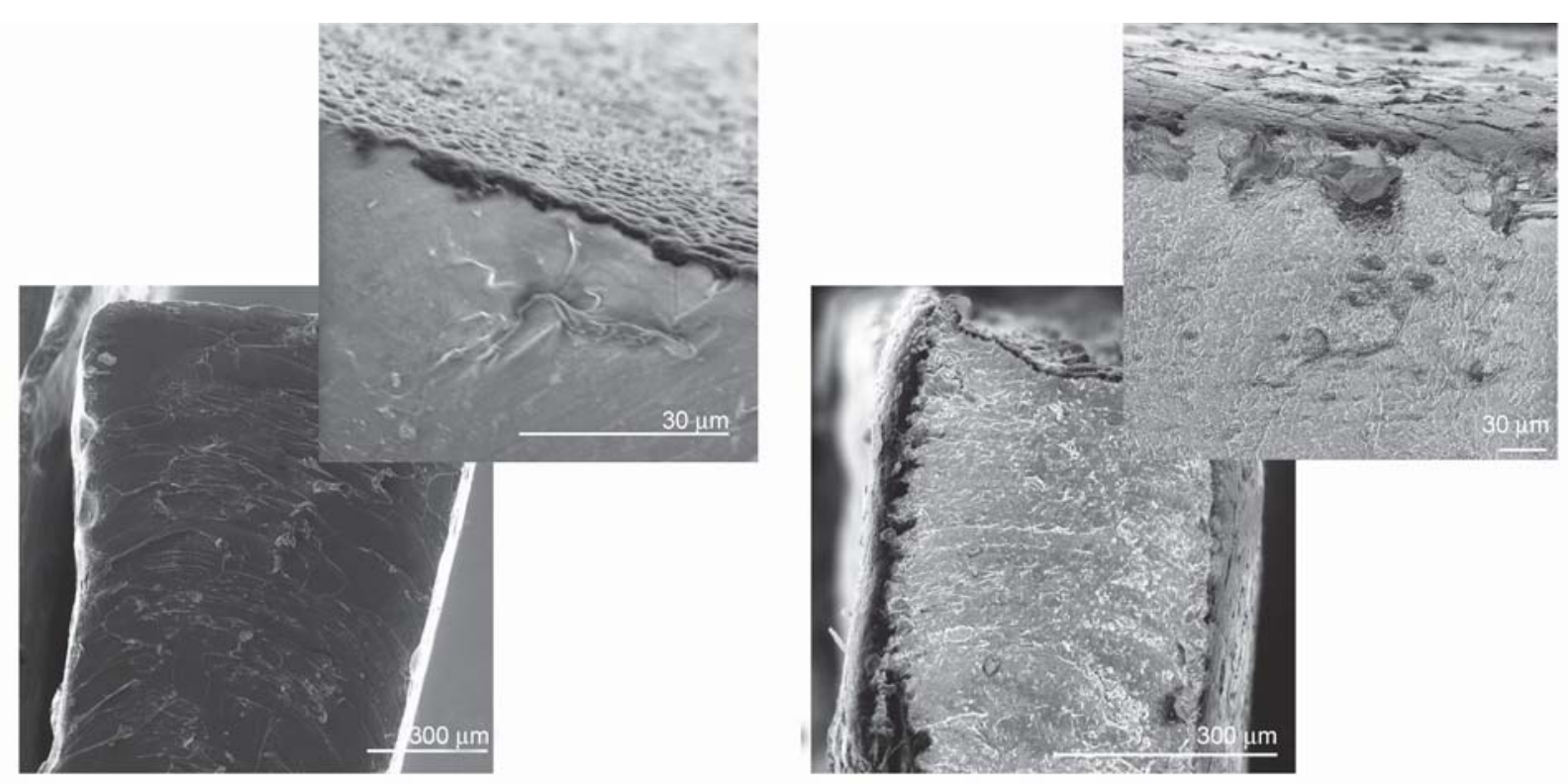

a)

b)
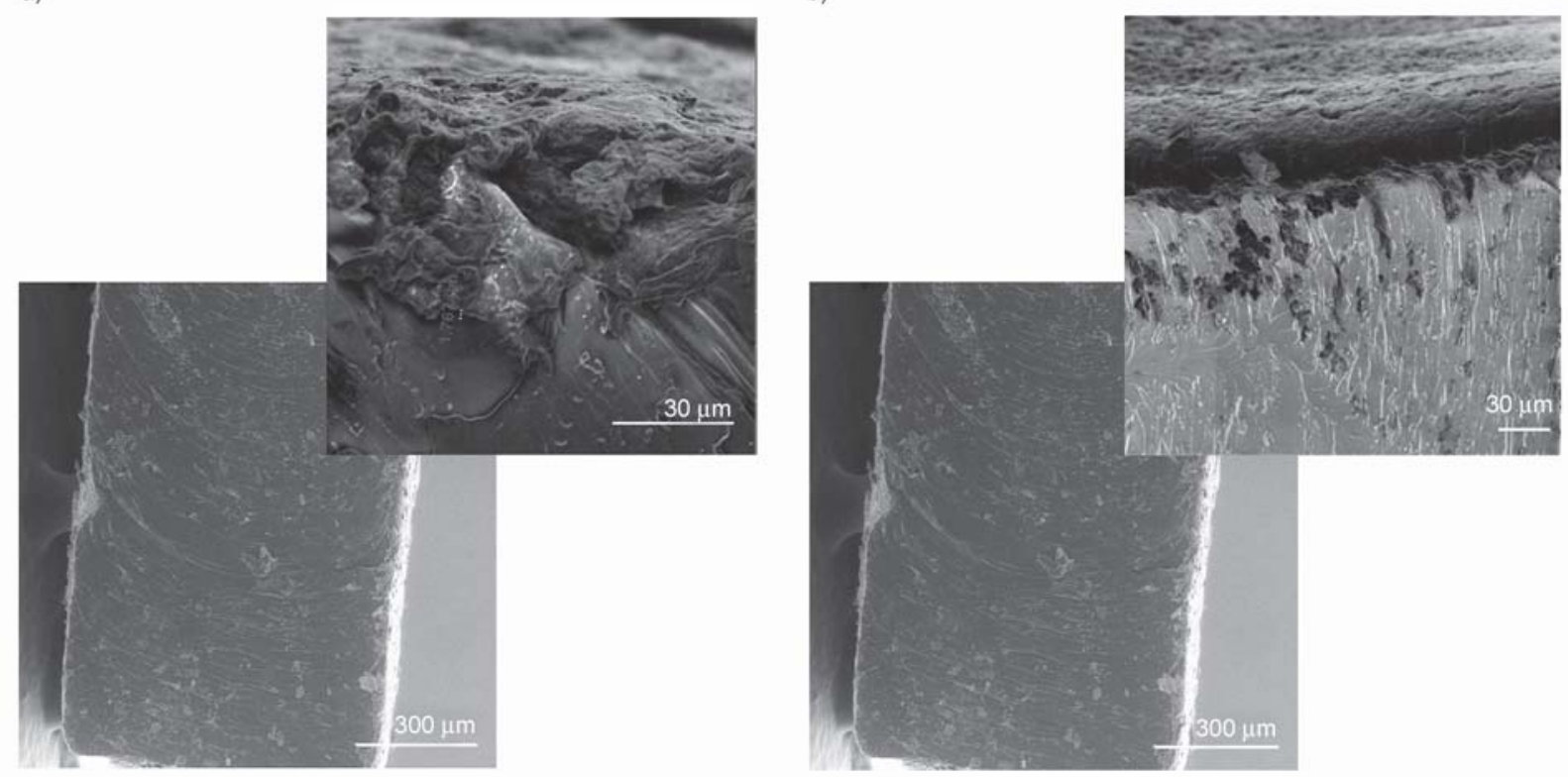

d)

Figure 13. SEM images for transversal cuts for a) WBPU/G, b) 5GE/G, c) WBPU/rGO and d) 5GO/rGO.

probably due to certain damage of the sample during the coating process. However, there is also a small increase in thermal stability, attributed to the $G$ and rGO shell protecting the material.

The coating of the systems was observed through SEM. For coated matrix, a sharper separation between the uncoated and coated parts can be observed, which seems less pronounced for coated composites, probably due to the better affinity of the coating to the $\mathrm{G}$ and $\mathrm{rGO}$ containing composites. This improved affinity helps the adhesion of the graphene and rGO flakes, which could result in a better conductivity for coated composites. Moreover, when analyzing transversal cuts of the composites, a good dispersion of the reinforcement in the matrix was corroborated,
Figure 13 shows a homogeneous surface with no visible agglomerations.

\section{Conclusions}

Parting from graphite flakes, graphene, and graphene oxide were obtained through mechanical and chemical methods, respectively. Graphene oxide was reduced by a thermal procedure. Results have shown the successful production of $\mathrm{G}, \mathrm{GO}$ and $\mathrm{rGO}$, and the changes in the structures have been observed in the different properties of the obtained carbon nanostructures. A significant existence of oxygen-containing groups in GO structure was determined by elemental analysis and was later corroborated by FTIR and TGA, while both graphene and reduced graphene 
oxide showed the absence or a very reduced amount of such groups. XRD analyses showed the breaking of the graphite structure in all systems, observed by the great decrease of intensity, and introduction of new groups in GO was deduced due to the increased d-spacing between the planes. By Raman spectroscopy the formation of defects in the nanostructure during the obtention processes were assessed, these defects were less pronounced for $G$ and even less so rGO, thanks to the lack of oxidized groups on their structures. Electrical conductivity analyses showed good conductivity for both $\mathrm{G}$ and rGO, whereas GO did not show conductive capacity.

On the other hand, a waterborne polyurethane matrix was synthesized from a polyol from a renewable source and was used as matrix to prepare composites reinforced with either graphene or graphene oxide. Salvia extract was used in order to disperse graphene in graphene containing composites. Graphene and reduced graphene oxide were later used as coating for WBPU and composites with the highest content of $\mathrm{G}$ and GO. WBPU, composites and coated systems have been characterized in order to study the effect produced by the addition of G, GO and rGO. Nanocomposites with enhanced mechanical and thermomechanical properties have been obtained. FTIR analysis showed $\mathrm{H}$-bonding interactions taken placed in composites. In the case of $\mathrm{GO}, \mathrm{H}$-bondings are formed between functional groups of nano-reinforcements and WBPU functional groups. However, in the case of G, H-bondings seemed to be formed between functional groups of polyurethane and plant extract functional groups. The better affinity between WBPU and GO is thought to have resulted in the better mechanical and thermomechanical properties seen in WBPU/GO composites, whereas the employed Salvia might have also influenced the changes in properties for WBPU/GE composites.

Lastly, a successful coating with graphene and reduced graphene oxide was achieved. The coated system exhibited electrical conductivity, being the conductive capacity higher for coated composites and, more so for rGO, attributed to a better affinity between composite and reinforcement due to the oxygen coating groups in the GO structure and the remaining ones in rGO. Moreover, DMA analyses showed that after the coating process, the thermomechanical performance was similar to uncoated systems.

\section{Acknowledgements}

Financial support from Basque Government (Grupos Consolidados IT776-13), University of the Basque Country (GIU18-216 research group), Spanish Ministry of Economy, Industry and Competitiveness (MAT2016-76294-R) is acknowledged. We also wish to acknowledge the 'Macrobehavior-Mesostructure-Nanotechnology' SGIker unit from the University of the Basque Country, for their technical support. I. L. thanks Basque Government for PhD Fellowship (PRE_2017_1_0085).

\section{References}

[1] Hu J., Peng K., Guo J., Shan D., Kim G. B., Li Q., Gerhard E., Zhu L., Tu W., Lv W., Hickner M. A., Yang J.: Click cross-linking-improved waterborne polymers for environment-friendly coatings and adhesives. ACS Applied Materials and Interfaces, 8, 17499-17510 (2016).

https://doi.org/10.1021/acsami.6b02131

[2] Santamaria-Echart A., Arbelaiz A., Saralegi A., Fernández-d'Arlas B., Eceiza A., Corcuera M. A.: Relationship between reagents molar ratio and dispersion stability and film properties of waterborne polyurethanes. Colloids and Surfaces A: Physicochemical and Engineering Aspects, 482, 554-561 (2015).

https://doi.org/10.1016/j.colsurfa.2015.07.012

[3] Madbouly S. A., Xia Y., Kessler M. R.: Rheological behavior of environmentally friendly castor oil-based waterborne polyurethane dispersions. Macromolecules, 46, 4606-4616 (2013).

https://doi.org/10.1021/ma400200y

[4] Lu Y., Larock R. C.: Soybean-oil-based waterborne polyurethane dispersions: Effects of polyol functionality and hard segment content on properties. Biomacromolecules, 9, 3332-3340 (2008).

https://doi.org/10.1021/bm801030g

[5] Korley L. S. T. J., Pate B. D., Thomas E. L., Hammond P. T.: Effect of the degree of soft and hard segment ordering on the morphology and mechanical behavior of semicrystalline segmented polyurethanes. Polymer, 47, 3073-3082 (2006).

https://doi.org/10.1016/j.polymer.2006.02.093

[6] Saralegi A., Rueda L., Martin L., Arbelaiz A., Eceiza A., Corcuera M. A.: From elastomeric to rigid polyurethane/cellulose nanocrystal bionanocomposites. Composites Science and Technology, 88, 39-47 (2013). https://doi.org/10.1016/j.compscitech.2013.08.025

[7] Saralegi A., Rueda L., Fernández-D’Arlas B., Mondragon I., Eceiza A., Corcuera M. A.: Thermoplastic polyurethanes from renewable resources: Effect of soft segment chemical structure and molecular weight on morphology and final properties. Polymer International, 62, 106-115 (2013).

https://doi.org/10.1002/pi.4330 
[8] Rodrigues S. N., Fernandes I., Martins I. M., Mata V. G., Barreiro F., Rodrigues A. E.: Microencapsulation of limonene for textile application. Industrial and Engineering Chemistry Research, 47, 4142-4147 (2008). https://doi.org/10.1021/ie800090c

[9] Guo Y-H., Guo J-J., Li S-C., Li X., Wang G-S., Huang Z.: Properties and paper sizing application of waterborne polyurethane emulsions synthesized with TDI and IPDI. Colloids and Surfaces A: Physicochemical and Engineering Aspects, 427, 53-61 (2013).

https://doi.org/10.1016/j.colsurfa.2013.03.017

[10] Nelson A. M., Long T. E.: Synthesis, properties, and applications of ion-containing polyurethane segmented copolymers. Macromolecular Chemistry and Physics, 215, 2161-2174 (2014).

https://doi.org/10.1002/macp.201400373

[11] Fang C., Zhou X., Yu Q., Liu S., Guo D., Yu R., Hu J.: Synthesis and characterization of low crystalline waterborne polyurethane for potential application in waterbased ink binder. Progress in Organic Coatings, 77, 6171 (2014).

https://doi.org/10.1016/j.porgcoat.2013.08.004

[12] Hoheisel T. N., Schrettl S., Szilluweit R., Frauenrath H.: Nanostructured carbonaceous materials from molecular precursors. Angewandte Chemie - International Edition, 49, 6496-6515 (2010).

https://doi.org/10.1002/anie.200907180

[13] Li C., Hui B., Ye L.: Construction of polyurethaneimide/graphene oxide nanocomposite foam with gradient structure and its thermal mechanical stability. Industrial and Engineering Chemistry Research, 57, 13742-13752 (2018).

https://doi.org/10.1021/acs.iecr.8b02911

[14] Kausar A.: Emerging research trends in polyurethane/ graphene nanocomposite: A review. Polymer-Plastics Technology and Engineering, 56, 1468-1486 (2017). https://doi.org/10.1080/03602559.2016.1277240

[15] Hadi A., Zahirifar J., Karimi-Sabet J., Dastbaz A.: Graphene nanosheets preparation using magnetic nanoparticle assisted liquid phase exfoliation of graphite: The coupled effect of ultrasound and wedging nanoparticles. Ultrasonics Sonochemistry, 44, 204-214 (2018). https://doi.org/10.1016/j.ultsonch.2018.02.028

[16] Hummers W. S., Offeman R. E.: Preparation of graphitic oxide. Journal of the American Chemical Society, 80, 1339 (1958).

https://doi.org/10.1021/ja01539a017

[17] Guerrero-Contreras J., Caballero-Briones F.: Graphene oxide powders with different oxidation degree, prepared by synthesis variations of the Hummers method. Materials Chemistry and Physics, 153, 209-220 (2015). https://doi.org/10.1016/j.matchemphys.2015.01.005

[18] Pei S., Cheng H-M.: The reduction of graphene oxide. Carbon, 50, 3210-3228 (2011).

https://doi.org/10.1016/j.carbon.2011.11.010
[19] Gómez-Navarro C., Burghard M., Weitz R. T., Scolari M., Mews A., Bittner A. M., Kern K.: Electronic transport properties of individual chemically reduced graphene oxide sheets. Nano Letters, 9, 3499-3503 (2007).

https://doi.org/10.1021/n1901209z

[20] Nguyen D. A., Lee Y. R., Raghu A. V., Jeong H. M., Shin C. M., Kim B. K.: Morphological and physical properties of a thermoplastic polyurethane reinforced with functionalized graphene sheet. Polymer International, 58, 412-417 (2009).

https://doi.org/10.1002/pi.2549

[21] Raghu A. V., Lee Y. R., Jeong H. M., Shin C. M.: Preparation and physical properties of waterborne polyurethane/functionalized graphene sheet nanocomposites. Macromolecular Chemistry and Physics, 209, 24872493 (2008). https://doi.org/10.1002/macp.200800395

[22] Hsiao S-T., Ma C-C. M., Tien H-W., Liao W-H., Wang Y-S., Li S-M., Huang Y-C.: Using a non-covalent modification to prepare a high electromagnetic interference shielding performance graphene nanosheet/water-borne polyurethane composite. Carbon, 60, 57-66 (2013). https://doi.org/10.1016/j.carbon.2013.03.056

[23] Shen B., Li Y., Zhai W., Zheng W.: Compressible graphene-coated polymer foams with ultralow density for adjustable electromagnetic interference (EMI) shielding. ACS Applied Materials and Interfaces, 8, 80508057 (2016).

https://doi.org/10.1021/acsami.5b11715

[24] Bansala T., Joshi M., Mukhopadhyay S.: Electromagnetic interference shielding behavior of chemically and thermally reduced graphene based multifunctional polyurethane nanocomposites: A comparative study. Journal of Applied Polymer Science, 136, 47666/1-47666/12 (2019).

https://doi.org/10.1002/app.47666

[25] Jiang Q., Liao X., Li J., Chen J., Wang G., Yi J., Yang Q., Li G.: Flexible thermoplastic polyurethane/reduced graphene oxide composite foams for electromagnetic interference shielding with high absorption characteristic. Composites Part A: Applied Science and Manufacturing, 123, 310-319 (2019).

https://doi.org/10.1016/j.compositesa.2019.05.017

[26] Verma M., Verma P., Dhawan S. K., Choudhary V.: Tailored graphene based polyurethane composites for efficient electrostatic dissipation and electromagnetic interference shielding applications. RSC Advances, 5, 97349-97358 (2015). https://doi.org/10.1039/c5ra17276d

[27] Santamaria-Echart A., Fernandes I., Barreiro F., Retegi A., Arbelaiz A., Corcuera M. A., Eceiza A.: Development of waterborne polyurethane-ureas added with plant extracts: Study of different incorporation routes and their influence on particle size, thermal, mechanical and antibacterial properties. Progress in Organic Coatings, 117, 76-90 (2018).

https://doi.org/10.1016/j.porgcoat.2018.01.006 
[28] Ugarte L., Gómez-Fernández S., Tercjak A., MartínezAmesti A., Corcuera M. A., Eceiza A.: Strain sensitive conductive polyurethane foam/graphene nanocomposites prepared by impregnation method. European Polymer Journal, 90, 323-333 (2017).

https://doi.org/10.1016/j.eurpolymj.2017.03.035

[29] González K., García-Astrain C., Santamaria-Echart A., Ugarte L., Avérous L., Eceiza A., Gabilondo N.: Starch/ graphene hydrogels via click chemistry with relevant electrical and antibacterial properties. Carbohydrate Polymers, 202, 372-381 (2018).

https://doi.org/10.1016/j.carbpol.2018.09.007

[30] Bragg W. L.: The diffraction of short electromagnetic waves by a crystal. Proceedings of the Cambridge Philosophical Society, 17, 43-57 (1913).

[31] Unalan I. U., Wan C., Trabattoni S., Piergiovanni L., Farris S.: Polysaccharide-assisted rapid exfoliation of graphite platelets into high quality water-dispersible graphene sheets. RSC Advances, 5, 26482-26490 (2015). https://doi.org/10.1039/c4ra16947f

[32] Raccichini R., Balduccu A., Varzi A., Passerini S.: Method of producing graphene by exfoliation of graphite. Word Patent 2015/131933A1 (2015.)

[33] Appel A-K., Thomann R., Mülhaupt R.: Polyurethane nanocomposites prepared from solvent-free stable dispersions of functionalized graphene nanosheets in polyols. Polymer, 53, 4931-4939 (2012).

https://doi.org/10.1016/j.polymer.2012.09.016

[34] Ghobadi M., Gharabaghi M., Abdollahi H., Boroumand Z., Moradian M.: $\mathrm{MnFe}_{2} \mathrm{O}_{4}$-graphene oxide magnetic nanoparticles as a high-performance adsorbent for rare earth elements: Synthesis, isotherms, kinetics, thermodynamics and desorption. Journal of Hazardous Materials, 351, 308-316 (2018).

https://doi.org/10.1016/j.jhazmat.2018.03.011

[35] Nethravathi C., Rajamathi M.: Chemically modified graphene sheets produced by the solvothermal reduction of colloidal dispersions of graphite oxide. Carbon, 46, 1994-1998 (2008).

https://doi.org/10.1016/j.carbon.2008.08.013

[36] Goncalves G., Marques P. A. A. P., Granadeiro C. M., Nogueira H. I. S., Singh M. K., Grácio J.: Surface modification of graphene nanosheets with gold nanoparticles: The role of oxygen moieties at graphene surface on gold nucleation and growth. Chemistry of Materials, 21, 4796-4802 (2009).

https://doi.org/10.1021/cm901052s

[37] Zhang X., Browne W. R., Feringa B. L.: Preparation of dispersible graphene through organic functionalization of graphene using a zwitterion intermediate cycloaddition approach. RSC Advances, 2, 12173-12176 (2012). https://doi.org/10.1039/c2ra22440b
[38] Dehghanzad B., Razavi Aghjeh M. K., Rafeie O., Tavakoli A., Oskooie J. A.: Synthesis and characterization of graphene and functionalized graphene via chemical and thermal treatment methods. RSC Advances, 6, 3578-3585 (2016).

https://doi.org/10.1039/c5ra19954a

[39] Khan M., Al-Marri A. H., Khan M., Mohri N., Adil S. F., Al-Warthan A., Siddiqui M. R. H., Alkhathlan H. Z., Berger R., Tremel W., Tahir M. N.: Pulicaria glutinosa plant extract: A green and eco-friendly reducing agent for the preparation of highly reduced graphene oxide. RSC Advances, 4, 24119-24125 (2014).

https://doi.org/10.1039/c4ra01296h

[40] Amina M., Al-Youssef H. M., Amna T., Hassan S., ElShafae A. M., Kim H. Y., Khil M-S.: Poly(urethane)/G. Mollis composite nanofibers for biomedical applications. Journal of Nanoengineering and Nanomanufacturing, 2, 85-90 (2012).

https://doi.org/10.1166/jnan.2012.1056

[41] Velasco-Vélez J. J., Jones T. E., Streibel V., Hävecker M., Chuang C-H., Frevel L., Plodinec M., Centeno A., Zurutuza A., Wang R., Arrigo R., Mom R., Hofmann S., Schlögl R., Knop-Gericke A.: Electrochemically active Ir NPs on graphene for OER in acidic aqueous electrolyte investigated by in situ and ex situ spectroscopies. Surface Science, 681, 1-8 (2019). https://doi.org/10.1016/j.susc.2018.10.021

[42] Mu S-J., Su Y-C., Xiao L-H., Liu S-D., Hu T., Tang H-B.: $\mathrm{X}$-ray diffraction pattern of graphite oxide. Chinese Physics Letters, 30, 096101/1-096101/9 (2013).

https://doi.org/10.1088/0256-307X/30/9/096101

[43] Krishnamoorthy K., Veerapandian M., Yun K., Kim S-J.: The chemical and structural analysis of graphene oxide with different degrees of oxidation. Carbon, 53, 38-49 (2013).

https://doi.org/10.1016/j.carbon.2012.10.013

[44] Lee M., Balasingam S. K., Jeong H. Y., Hong W. G., Lee H-B-R., Kim B. H., Jun Y.: One-step hydrothermal synthesis of graphene decorated $\mathrm{V}_{2} \mathrm{O}_{5}$ nanobelts for enhanced electrochemical energy storage. Scientific Reports, 5, 8151/1-8151/8 (2015).

https://doi.org/10.1038/srep08151

[45] Saiful Badri M. A., Salleh M. M., Md Noor N. F., Rahman M. Y. A., Umar A. A.: Green synthesis of fewlayered graphene from aqueous processed graphite exfoliation for graphene thin film preparation. Materials Chemistry and Physics, 193, 212-219 (2017).

https://doi.org/10.1016/j.matchemphys.2017.02.029

[46] Gayathri S., Jayabal P., Kottaisamy M., Ramakrishnan V.: Synthesis of few layer graphene by direct exfoliation of graphite and a Raman spectroscopic study. AIP Advances, 4, 027116/1-027116/12 (2014).

https://doi.org/10.1063/1.4866595

[47] Eckmann A., Felten A., Mishchenko A., Britnell L., Krupke R., Novoselov K. S., Casiraghi C.: Probing the nature of defects in graphene by Raman spectroscopy. Nano Letters, 12, 3925-3930 (2012).

https://doi.org/10.1021/n1300901a 
[48] Perumbilavil S., Sankar P., Rose T. P., Philip R.: White light Z-scan measurements of ultrafast optical nonlinearity in reduced graphene oxide nanosheets in the 400 $700 \mathrm{~nm}$ region. Applied Physics Letters, 107, 051104/1051104/5 (2015).

https://doi.org/10.1063/1.4928124

[49] Luo H., Dong J., Yao F., Yang Z., Li W., Wang J., Xu X., Hu J., Wan Y.: Layer-by-layer assembled bacterial cellulose/graphene oxide hydrogels with extremely enhanced mechanical properties. Nano-Micro Letters, 10, 42/1-42/10 (2018).

https://doi.org/10.1007/s40820-018-0195-3

[50] Marinho B., Ghislandi M., Tkalya E., Koning C. E., de With G.: Electrical conductivity of compacts of graphene, multi-wall carbon nanotubes, carbon black, and graphite powder. Powder Technology, 221, 351-358 (2012). https://doi.org/10.1016/j.powtec.2012.01.024

[51] Krishnan K. S., Ganguli N.: Large anisotropy of the electrical conductivity of graphite. Nature, 144, 667 (1939). https://doi.org/10.1038/144667a0

[52] Ugarte L., Fernández-d'Arlas B., Valea A., González M. L., Corcuera M. A., Eceiza A.: Morphology-properties relationship in high-renewable content polyurethanes. Polymer Engineering and Science, 54, 2282 2291 (2014).

https://doi.org/10.1002/pen.23777

[53] Santamaria-Echar A., Fernandes I., Saralegi A., Costa M. R. P. F. N., Barreiro F., Corcuera M. A., Eceiza A.: Synthesis of waterborne polyurethane-urea dispersions with chain extension step in homogeneous and heterogeneous media. Journal of Colloid and Interface Science, 476, 184-192 (2016).

https://doi.org/10.1016/j.jcis.2016.05.016

[54] Pei A., Malho J. M., Ruokolainen J., Zhou Q., Berglund L. A.: Strong nanocomposite reinforcement effects in polyurethane elastomer with low volume fraction of cellulose nanocrystals. Macromolecules, 44, 4422-4427 (2011). https://doi.org/10.1021/ma200318k

[55] Song W., Wang B., Fan L., Ge F., Wang C.: Graphene oxide/waterborne polyurethane composites for fine pattern fabrication and ultrastrong ultraviolet protection cotton fabric via screen printing. Applied Surface Science, 463, 403-411 (2019).

https://doi.org/10.1016/j.apsusc.2018.08.167

[56] Wan T., Chen D.: Mechanical enhancement of selfhealing waterborne polyurethane by graphene oxide. Progress in Organic Coatings, 121, 73-79 (2018). https://doi.org/10.1016/j.porgcoat.2018.04.016
[57] Bernard C., Goodwin D. G., Gu X., Celina M., Nyden M., Jacobs D., Sung L., Nguyen T.: Graphene oxide/waterborne polyurethane nanocoatings: Effects of graphene oxide content on performance properties. Journal of Coatings Technology and Research, 17, 255-269 (2020). https://doi.org/10.1007/s11998-019-00267-6

[58] Pokharel P., Pant B., Pokhrel K., Pant H. R., Lim J-G., Lee D. S., Kim H-Y., Choi S.: Effects of functional groups on the graphene sheet for improving the thermomechanical properties of polyurethane nanocomposites. Composites Part B: Engineering, 78, 192-201 (2015).

https://doi.org/10.1016/j.compositesb.2015.03.089

[59] Pokharel P., Lee D. S.: Thermal and mechanical properties of reduced graphene oxide/polyurethane nanocomposite. Journal of Nanoscience and Nanotechnology, 14, 5718-5721 (2014). https://doi.org/10.1166/jnn.2014.8824

[60] Lei L., Xia Z., Zhang L., Zhang Y., Zhong L.: Preparation and properties of amino-functional reduced graphene oxide/waterborne polyurethane hybrid emulsions. Progress in Organic Coatings, 97, 19-27 (2016). https://doi.org/10.1016/j.porgcoat.2016.03.011

[61] Sang L., Hao W., Zhao Y., Yao L., Cui P.: Highly aligned graphene oxide/waterborne polyurethane fabricated by in-situ polymerization at low temperature. e-Polymers, 18, 75-84 (2018). https://doi.org/10.1515/epoly-2017-0141

[62] Ou C-W., Su C-H., Jeng U-S., Hsu S-H.: Characterization of biodegradable polyurethane nanoparticles and thermally induced self-assembly in water dispersion. ACS Applied Materials and Interfaces, 6, 5685-5694 (2014). https://doi.org/10.1021/am500213t

[63] Fuensanta M., Jofre-Reche J. A., Rodríguez-Llansola F., Costa V., Iglesias J. I., Martín-Martínez J. M.: Structural characterization of polyurethane ureas and waterborne polyurethane urea dispersions made with mixtures of polyester polyol and polycarbonate diol. Progress in Organic Coatings, 112, 141-152 (2017). https://doi.org/10.1016/j.porgcoat.2017.07.009

[64] Kumar M., Chung J. S., Kong B-S., Kim E. J., Hur S. H.: Synthesis of graphene-polyurethane nanocomposite using highly functionalized graphene oxide as pseudocrosslinker. Materials Letters, 106, 319-321 (2013). https://doi.org/10.1016/j.matlet.2013.05.059

[65] Zhang J., Zhang C., Madbouly S. A.: In situ polymerization of bio-based thermosetting polyurethane/ graphene oxide nanocomposites. Journal of Applied Polymer Science, 132, 41751/1-41751/8 (2015). https://doi.org/10.1002/app.41751 